\title{
THE CRITERIA OF CRIMINAL RESPONSIBILITY
}

\author{
HERBERT WECHSLER†
}

$\mathrm{T}$

HE LONG-SUSTAINED ATTACK on the $M^{\prime} N$ aghten rules, mounted by most psychiatrists and many lawyers, has had significant chairmanship of Sir Ernest Gowers, reporting in September 1953, agreed with only one dissenting voice that "the test of responsibility laid down by the ... Rules is so defective that the law on the subject ought to be changed." A majority of the commission urged the total abrogation of the rules, leaving the jury "to determine whether at the time of the act the accused was suffering from disease of the mind (or mental deficiency) to such a degree that he ought not to be held responsible." Three members were opposed to the elimination of the rules but favored their extension to hold irresponsible a person who "at the time of committing the act" and "as a result of disease of the mind (or mental deficiency) . . . was incapable of preventing himself from committing it," a proposal the majority of the commission also viewed as an improvement on the present law. ${ }^{1}$ While these British submissions have not yet been acted on in England, ${ }^{2}$ they have already had an important influence on us. Last May the Supreme Court of $\mathrm{New}$ Mexico, pointing to the report of the commission, followed the advice of its minority. "Assuming defendant's knowledge of the nature and quality of his act and his knowledge that the act is wrong, if, by reason of disease of the mind, defendant has been deprived of or has lost the power of his will which would enable him to prevent himself from doing the act," the court declared that "he can not be found guilty."3 And last July in Durham v. United States, a bench of the Court of

† Professor of Law, Columbia University.

${ }^{2}$ Royal Commission on Capital Punishment 1949-1953, Report 110-11, 116, 285-87 (Cmd. 8932).

${ }^{2}$ Exceedingly acidulous reactions to the Report were expressed in the House of Lords, though less on this point than on others. See 185 The Parliamentary Debates (Hansard) 137-88, esp. 140, 159, 177-78, 183, 185 (5th ser., 1953). The government has thus far staved off a discussion in the House of Commons.

${ }^{8}$ State v. White, - N.M. -, - 270 P. 2d 727, 731 (1954). 
Appeals for the District of Columbia, also impressed by the report of the commission, undertook to reformulate the District common law by prescribing as the governing criterion "simply that an accused is not criminally responsible if his unlawful" act was the product of mental disease or mental defect."

The Durham decision will undoubtedly be hailed in many quarters as a welcome if belated step in the accommodation of the penal law to modern psychiatric knowledge, a milestone in the path toward a more scientific legal process. Devoutly as such consummations should be wished, the court's action seems to me to present major difficulties with respect to both result and rationale. To state these difficulties briefly is the purpose of this comment.

First: The initial difficulty inheres in determining the meaning of the principle laid down. The three crucial terms in the court's formulation are "disease," "defect" and "product." None is defined in Judge Bazelon's opinion.

The court does tell us that "disease" is used "in the sense of a condition which is considered capable of either improving or deteriorating," "defect" in the sense of a condition which is not capable of such change "and which may be either congenital, or the result of injury, or the residual effect of a physical or mental disease." Beyond distinguishing between conditions that are changeable and fixed, this leaves the meaning of disease or defect wholly indeterminate. On these definitions it is difficult to see how any abnormalities that have a psychical dimension can be excluded from the meaning of the terms. ${ }^{\overline{5}}$

P. 874-75.

${ }^{5}$ This view is supported by Stewart v. United States, 214 F. 2d 879 (App. D.C., 1954), decided two weeks after Durham. Compare the narrower meaning accorded to "disease" by the Royal Commission on Capital Punishment, op. cit. supra note 1, at 73:

"We use 'mental abnormality' as a general term to cover all forms of mental disease, mental deficiency and disorders of personality. ... .

"By 'mental disease' or 'disease of the mind,' we mean a pathological change arising de novo in the mind of an individual who has already progressed some way towards maturity or has attained it. We recognize that mental disease may occur in children, adolescents or adults, in persons of retarded or of normal intelligence, and in persons of normal or of psychopathic temperament. We conceive, however, that the implications of the word 'disease' are that a new element of mental deterioration or disorganization is introduced, bringing with it a qualitative departure from the previously established norm. For us, therefore, mental disease is only one part of mental disorders of all kinds, and broadly corresponds to what are often called major diseases of the mind, or psychoses; although it may also arise in cases, such as those of epilepsy or cerebral tumor, which are not ordinarily regarded by doctors as psychotic. Among the psychoses are the conditions known as schizophrenia, manic-depressive psychoses, and organic disease of 
There is some explication of the meaning of "product." The court indicates that the jury should be charged that even though the accused suffered from a mental disease or defect he "would still be responsible for his unlawful act if there was no causal connection between such mental abnormality and the act." In a footnote to this statement the court sets forth the following quotation from the Report of the Royal Commission: ${ }^{7}$

There is no a priori reason why every person suffering from any form of mental abnormality or disease, or from any particular kind of mental disease, should be treated by the law as not answerable for any criminal offense which he may commit, and be exempted from conviction and punishment. Mental abnormalities vary infinitely in their nature and intensity and in their effects on the character and conduct of those who suffer from them. Where a person suffering from a mental abnormality commits a crime, there must always be some likelihood that the abnormality has played some part in the causation of the crime; and, generally speaking, the graver the abnormality, [and the more serious the crime, ${ }^{8}$ the more probable it must be that there is a causal connection between them. But the closeness of this connection will be shown by the facts brought in evidence in individual cases and cannot be decided on the basis of any general medical principle. ${ }^{9}$

From these materials it seems quite clear that the breadth of the Durham formulation turns mainly on the concept of causality that the court contemplates should animate its operation. This is, of course, a difficult and subtle matter. The old New Hampshire opinions, from which the "product" test was drawn, cast little light upon the issue; and such teaching as they give we may believe the Durham court would disavow. For these opinions postulate a clear antithesis between a human action produced by disease and one that is the product of volition and intention. "When disease is the propelling, uncontrollable power, the man," Judge Doe said, "is as innocent as the weapon,- the

the brain. Other conditions, not included under this term, are the minor forms of mental disorder-the neurotic reactions such as neurasthenia, anxiety states and hysteria-and the disorders of development of the personality-psychopathic personality. We are aware that this classification will not be unconditionally endorsed by all psychiatrists, and that some would prefer to include under the term 'disease of the mind' even the minor abnormalities we have referred to. We believe, however, that the nature of the distinction we have drawn will be clear to them, and will be acceptable to them as the basis for a discussion of criminal responsibility."

'P. 875.

${ }^{\top}$ Royal Commission on Capital Punishment, op. cit. supra note 1, at 99.

${ }^{8}$ The bracketed words are omitted in the court's quotation.

P. 875 . 
mental and moral elements are as guiltless as the material."10 So too Judge Ladd:

If the defendant had an insane impulse to kill his wife, which he could not control, then mental disease produced the act. If he could have controlled it, then his will must have assented to the act, and it was not caused by disease, but by the concurrence of his will, and was therefore crime.11

This is to call not merely for "a causal relationship" between disease and act but for a specific mode of causality, namely, the total destruction of the actor's capacity for self-control, the nonconcurrence of his "will." "12

I say that this is not the teaching of the Durham case because if it were, the decision would not work a change in pre-existing law, as it purports to do. Since 1929 the District has not been governed by the M'Naghten rules simpliciter. Responsibility has been excluded if the accused was bereft of the cognitive capacity to know the nature and quality of his act or that his act was wrong. It has also been excluded, however, if "his reasoning powers were so far dethroned by his diseased mental condition as to deprive him of the will power to resist the insane impulse to perpetrate the deed, though knowing it to be wrong." ${ }^{13}$ How can an action be the product of disease, in the New Hampshire sense of the complete exclusion of volition, unless it falls within one of the categories of these pre-existing tests ${ }^{14}$

${ }^{20}$ State v. Pike, 49 N.H. 399, 441 (1870).

${ }^{21}$ State v. Jones, 50 N.H. 369, 399 (1871).

${ }^{12}$ That the New Hampshire judges should have viewed disease and will as mutually exclusive causes of behavior may be explained by their acceptance of the prevailing medical view of insanity as always derived from an abnormal condition of the brain. Cf. Ray, Treatise on the Medical Jurisprudence of Insanity 41 (3d ed., 1853): "In short, madness is the result of a certain pathological condition of the brain, while the criminal effects of violent passions merely indicate unusual strength of those passions, or a deficient education of those higher faculties that furnish the necessary restraint upon their power." See also ibid., at 3, 69-73, 128-30, 166, 291-92, 315, 335. How central this point was for Judge Doe is made clear by a letter to Dr. Tyler set forth in Reik, The Doe-Ray Correspondence, 63 Yale L.J. 183, 187 (1953). There is considerable irony, therefore, in the modern, dynamic, functional psychiatrist's disposition to regard the DoeRay conclusions as gospel on the subject of the legal tests.

${ }^{13}$ Smith v. United States, 36 F. 2d 548, 549 (App. D.C., 1929).

${ }^{14}$ The court suggests one possibility: that the word "impulse" implies "sudden, momentary or spontaneous inclinations" as distinguished from insane propulsions attended by brooding or reflection. The point was made by the Royal Commission but the implication hardly seems intrinsic to the meaning of the word nor is it shown to be an aspect of its legal meaning in the District. In any case, if this is a real problem, it could have been met so simply by reformulation of this aspect of the test [cf. State v. White, N.M. - - - 270 P. 2d 727, 731 (1954) ], that I cannot regard it as a major element in the decision. The court quite plainly meant to jettison criteria that require the complete exclusion of volition. 
Assuming then that the causality relationship that the court of appeals would deem sufficient need not inhere in a total incapacity for the cognition or the inhibition incident to self-control, what is the question for the trier of the facts? Whether an accused who suffered from a mental abnormality would have committed the otherwise criminal act under the given circumstances even if he had not suffered from the abnormality involved? If so, an answer that he would have done so surely can be given very rarely; the concepts of mental disease and defect imply at least an abnormality that has some impact of importance on the conscious or unconscious life of the defendant. ${ }^{15}$ Yet the court can hardly contemplate that evidence of mental abnormality should in itself suffice to negative responsibility. This position would preclude conviction in most cases where the crime is one abhorrent to the ordinary conscience; the fact of its commission is some indication of such abnormality. Moreover, this position was before the court as one of the submissions of appointed counse ${ }^{16}$ and was impliedly rejected when the court insisted on a finding of causality.

The logic of the situation points, therefore, to the development of causal concepts less relaxed than but-for cause but less demanding than complete exclusion of volition, as required by the antecedent tests. That this necessity is not acknowledged in the court's opinion and that no attempt is made at the elucidation of the causal standard for the jury seems to me quite indefensible. On the opinion as it stands would any juryman be wrong if he insisted that the test of "a causal relationship" is satisfied on evidence of but-for cause alone?

It will no doubt be answered that the problem for the jury is to give importance to causal relationships that satisfy its sense of justice in relation to a criminal conviction. This is suggested by the statement of the court that juries

will continue to make moral judgments, still operating under the fundamental precept that "Our collective conscience does not allow punishment where it cannot impose blame." But in making such judgments, they will be guided by wider horizons of knowledge concerning mental life. ${ }^{17}$

\footnotetext{
${ }^{\text {Is }}$ It will be recalled that the Medico-Psychological Association of Great Britain and Ireland proposed to the Atkin Committee that an accused should be adjudged irresponsible unless it is "proved to the satisfaction of the jury that his crime was unrelated to his mental disorder." The committee rejected the proposal on the ground that the burden on the prosecution could not be discharged. See East, Forensic Psychiatry 63-64 (1927).

${ }^{20}$ See Brief for Appellant at 28-29, 32 (filed by Messrs. Abe Fortas and Abe Krash).

${ }^{27}$ P. 876.
} 
If we assume, however, that the purpose of the court is to submit the issue to the sense of justice of a jury informed, so far as experts can inform it, about the psychic life of the defendant, would it not be preferable to present the question in these terms? Under the charge now sanctioned by the court, the jury must disregard one meaning of the term "causal relationship," perhaps, indeed, its most pervasive meaning, in favor of another that the court does not express.

It is not difficult, of course, to leave the question to the jury's sense of justice, if that is the result that one desires to achieve. The Royal Commission majority suggested one approach: to ask if the accused was suffering from mental disease or defect "to such a degree that he ought not to be held responsible." Another formulation, preferable in my view, is to submit the question whether the capacity of the accused to control his conduct in accordance with the law was impaired so greatly that he cannot justly be held criminally responsible. To put the matter in this latter way makes perfectly explicit the extent of the departure from the antecedent tests. Where formerly responsibility obtained in the absence of complete impairment of the powers relevant to self-control of the forbidden act, the jury now may hold impairment less than total to suffice. And since impairment is a matter of degree, if the extreme condition is no longer necessary, the precise degree demanded must be governed by the sense of justice of the triers of the facts.

Whether this translation of the Durham test would be accepted by the court, I have, of course, no way of knowing. I do say, however, that if Durham stands, this is the only way to give it meaning consonant with what appears to be its purpose. The only causal concept that has bearing on the justice of conviction is one in which the causal mode inheres in the impairment of capacity for self-control.

Second: I should feel more confident in this interpretation were it not for the opinion of the court. For the opinion does not face the question of how extensively capacity must be impaired to call for holding the defendant irresponsible. The rationale of decision is presented in entirely different terms.

To put the matter briefly, the court regards the fundamental defect in the criteria it now has superseded to be that they make responsibility depend upon particular symptoms of mental disease or defect. Thus: "In attempting to define insanity in terms of a symptom, the courts have assumed an impossible role, not merely one for which they 
have no special competence."18 Again: under the "product" test, "the jury will not be required to rely on such symptoms as criteria for determining the ultimate question of fact ..."; the "question will be simply whether the accused acted because of a mental disorder, and not whether he displayed particular symptoms which medical science has long recognized do not necessarily, or even typically, accompany even the most serious mental disorder."19

This analysis of the criteria has often been presented, particularly by their psychiatric critics, but it involves a fundamental error that is not reduced by repetition. If the legal criteria are viewed as an attempt to define mental disease by the enumeration of its symptoms, they are, of course, both unintelligible and presumptuous. Why should they be so regarded? Is it the law that mental disorder ipso facto establishes irresponsibility? Could anyone embrace it as the law without assuring himself that the term disorder would imply the relevant impairment of capacity? As courts and commentators have repeated to the point of tedium, the criteria are addressed to the question of when disorder or defect should be accorded the specific legal consequence of a defense to criminal conviction, with the specific differences in dealing with the individual that this specific legal consequence entails. Thus the criteria are not concerned with the indicia of diagnosis of disease; they are concerned with the effects that a disease must have on the defendant if it is to work the exculpation claimed. The effects they make material are those that bear, as I have shown, on the capacity of the actor for selfcontrol. M'Naghten may be challenged, to be sure, upon the ground that it confines inquiry to the actor's cognitive capacity; more is involved in the capacity for self-control. It may be urged that irresistible impulse, in its ordinary formulation, calls for findings too extreme. These are both relevant and arguable matters. But I submit that it cannot be urged with any show of reason that these criteria should be rejected on the ground that they purport to catalogue the symptoms of defect or of disease.

Durham then puts forth, in my opinion, a legal principle beclouded by a central ambiguity, both unexplained and unsupported by its basic rationale. Despite this, I believe that it is possible to give it meaning: that responsibility may be negated by disease or by defect if it impairs capacity sufficiently, according to the jury's sense of justice.

\footnotetext{
${ }^{28}$ P. 872.

${ }^{20}$ P. 873-74.
} 
Third: If my interpretation of the Durham test is valid, there remains the question whether such a change in law is wise, an issue on which we unhappily derive small help from the opinion.

There are impressive arguments against the change which run substantially as follows:

The purpose of the penal law is to express a formal social condemnation of forbidden conduct, buttressed by sanctions calculated to prevent it-not alone by incapacitating and so far as possible correcting the offending individual, but also by their impact on the general imagination, i.e., through the medium of general deterrence. Considerations of equality and of effectiveness conspire to demand that sanctions which are threatened generally be applied with generality upon conviction-not that the sentence disregard differences in circumstances or in individuals but that the sentence be imposed within the framework of such formal condemnation and conviction. Responsibility criteria define a broad exception. The theory of the exception is that it is futile thus to threaten and condemn persons who through no fault of their own are wholly beyond the range of influence of threatened sanctions of this kind. So long as there is any chance that the preventive infiuence may operate, it is essential to maintain the threat. If it is not maintained, the influence of the entire system is diminished upon those who have the requisite capacity, albeit that they sometimes may offend.

On this analysis, the category of the irresponsible must be defined in extreme terms. The problem is to differentiate between the wholly non-deterrable and persons who are more or less susceptible to influence by law. The category must be so extreme that to the ordinary man, burdened by passion and beset by large temptations, the exculpation of the irresponsibles bespeaks no weakness in the law. He does not identify himself and them; they are a world apart. This will be found to be the case in every instance where $M^{\prime} N a g h t e n$ operates; ${ }^{20}$ with tight administration that distinguishes with care between the irresistible and unresisted impulse, it is the case under this test as well, though doubts about the possibility of such administration surely have their point. Beyond such extreme incapacities, however, the exception cannot go. This, to be sure, is not poetic justice. It is public justice, which in the interest of the common good prescribes a standard all must strive to satisfy who can, those whose nature or nurture leads

\footnotetext{
${ }^{20}$ For a detailed demonstration of this point, see Wechsler and Michael, A Rationale of the Law of Homicide, 37 Col. L. Rev. 701, 752-57 (1937).
} 
them to conform with difficulty no less than those who find compliance easy. ${ }^{21}$ Only so can the general effort be required and maintained. If finer distinctions are in order, let them be weighed with other factors that have bearing on the nature of the sentence and the mitigations that at that point may be made.

These are not, in my view, easy arguments to answer. Much would be said, of course, by those who disavow the basic premises about the penal law, viewing the condemnatory-punitive aspect of criminal conviction as unjust and irrational in any case. From this point of view, rooted in a kind of psychiatric crypto-ethics not uncommon in our culture, anything that prefers commitment to conviction is desirable; you go as far in this direction as you can. ${ }^{22}$ But this is not the view embraced by Durham and I put it to one side. What can be said within the framework of the present legal system, compatible with its assumptions, its objectives and ideals?

The most important counter-argument is, it seems to me, that the extreme categories are too extreme for practical administration; the specific questions that they put before the psychiatric witness or examiner call for a finding so severe that it must rest too largely on conjecture, even with persons whose capacity is most impaired. This is to say that to insist on the distinction between total impairment of capacity and an impairment of a very high degree, while workable in cases such as epileptic seizure and perhaps with some delusional psychoses, presents elsewhere too great difficulty in administration for the effort at distinction to be made. So long, indeed, as law persists in the distinction, it is likely to be nullified in practice, with attendant difficulties in the presentation and evaluation of the psychiatric evidence on which administration of the law depends. Some jurisdictions, for example, solve the problem now by simply not bringing psychotics to a trial; they are committed in its stead.

This is an argument of weight. Many psychiatrists who do forensic work and are not disaffected with respect to penal law in general would

${ }^{21}$ For a judicious appraisal of this point from the points of view of law, psychiatry and Christian ethics, see Sir Walter Moberly, Responsibility (1951).

${ }^{2}$ The humanity thought to inhere in this approach is far from undiluted. Cf. ibid., at 20: "The desire to excuse people who labor under handicaps, however kindly in intention, may be a cruel kindness, for in the long run it must impair their status in the community. In a well-meant endeavor to spare them we may unwittingly inflict on them an injury deeper and more irremediable than any which now threatens them. Men whose case is wholly pathological are disqualified for freedom. No man can contract out of his social obligations on the plea of moral incapacity without thereby abdicating his right to the direction of his own life." 
make it with extreme conviction. Their difficulty would be met, with consequent improvement in the quality and candor of their evidence, if they could cast their opinions as to impairment of capacity in terms of judgments of degree. And if the jury were admonished (or the court when it must try the facts acknowledged) that only a very high degree of incapacity warrants finding irresponsibility, would not the attainable objectives of the law be met? Such a formulation would seem fairly to exclude undifferentiated psychopaths who in the present state of psychiatric knowledge must, it seems to me, be viewed as problems to be dealt with by conviction and correction; ${ }^{23}$ that would, at least, be a condition, in my view, of its acceptability.

Surely, if this had been the case presented by the Durham court, one would be hesitant to urge that it is wrong. So long at least as Fisher $v$. United States ${ }^{24}$ survives and impairment of capacity may not be adduced in mitigation on a capital conviction (as it might affect a sentence less than capital) ${ }^{25}$ the demand that something less than total incapacity be relevant upon the question of responsibility has a persuasive voice. But whether the retention of the strict criteria, coupled with admission of the psychiatric evidence in mitigation, ${ }^{26}$ might not yield a better result-puts for me a most perplexing question.

\footnotetext{
${ }^{23}$ See, e.g., Royal Commission on Capital Punishment, op. cit. supra note 1, at 137: "This abnormality is a statistical abnormality; that is to say, the psychopath differs from a normal person only quantitatively or in degree, not qualitatively; and the diagnosis of psychopathic personality does not carry with it any explanation of the causes of the abnormality." Cf. Cleckley, The Mask of Sanity 396-98, 416-19 (2d ed., 1950) ; Neustatter, Psychological Disorder and Crime 87-100 (1953).

As Paul Tappan has put it, to channel psychopaths from prisons to mental hospitals is more likely to convert the hospitals into prisons than to work much benefit even to the psychopaths themselves. Stewart v. United States, 214 F. 2d 879 (App. D.C., 1954), indicates, however, that under Durham evidence that the accused was a psychopath will suffice to require the submission of the issue of responsibility to the jury.
}

${ }^{24} 149$ F. 2d 28 (App. D.C., 1945), aff'd 328 U.S. 463 (1946).

${ }^{25}$ In Stewart v. United States, 214 F. 2d 879 (App. D.C., 1954), Mr. Abram Chayes as amicus curiae appointed by the court urged that Fisher be overruled. The court, reversing the conviction on other grounds, concluded that reconsideration of Fisher "should wait until we can appraise the results of the broadened test of criminal responsibility which we recently announced in Durham."

${ }^{28} \mathrm{~A}$ wholly satisfactory basis for this result might well require legislation. 